\title{
The oral VEGF receptor tyrosine kinase inhibitor pazopanib in combination with the MEK inhibitor trametinib in advanced cholangiocarcinoma
}

\author{
Rachna T Shroff ${ }^{1,3}$, Mark Yarchoan ${ }^{2,3}$, Ashley O'Connor ${ }^{2}$, Denise Gallagher ${ }^{2}$, Marianna L Zahurak ${ }^{2}$, \\ Gary Rosner ${ }^{2}$, Chimela Ohaji ${ }^{1}$, Susan Sartorius-Mergenthaler ${ }^{2}$, Vivek Subbiah ${ }^{1}$, Ralph Zinner ${ }^{1}$ \\ and Nilofer S Azad ${ }^{\star}, 2$
}

${ }^{1}$ The University of Texas MD Anderson Cancer Center, 1515 Holcombe Boulevard Unit 426, Houston, TX 77030, USA and ${ }^{2}$ Gastrointestinal Oncology, Sidney Kimmel Comprehensive Cancer Center, Johns Hopkins University, 1650 Orleans Street, Room 4M10, Baltimore, MD 21287, USA

\begin{abstract}
Background: Cholangiocarcinoma is an aggressive malignancy with limited therapeutic options. MEK inhibition and antiangiogenic therapies have individually shown modest activity in advanced cholangiocarcinoma, whereas dual inhibition of these pathways has not been previously evaluated. We evaluated the safety and efficacy of combination therapy with the oral VEGF receptor tyrosine kinase inhibitor pazopanib plus the MEK inhibitor trametinib in patients with advanced cholangiocarcinoma.
\end{abstract}

Methods: In this open-label, multicentre, single-arm trial, adults with advanced unresectable cholangiocarcinoma received pazopanib $800 \mathrm{mg}$ daily and trametinib $2 \mathrm{mg}$ daily until disease progression or unacceptable toxicity. The primary end point was progression-free survival (PFS) with secondary end points including overall survival (OS), response rate, and disease control rate (DCR).

Results: A total of 25 patients were enrolled and had received a median of 2 prior systemic therapies (range 1-7). Median PFS was 3.6 months (95\% Cl: 2.7-5.1) and the 4-month PFS was 40\% (95\% Cl: 24.7-64.6\%). There was a trend towards increased 4-month PFS as compared with the prespecified null hypothesised 4-month PFS of $25 \%$, but this difference did not reach statistical significance ( $P=0.063)$. The median survival was 6.4 months $(95 \% \mathrm{Cl}: 4.3-10.2)$. The objective response rate was $5 \%(95 \% \mathrm{Cl}$ : $0.13-$ $24.9 \%$ ) and the DCR was $75 \%$ (95\% Cl: 51\%,91\%). Grade 3/4 adverse events attributable to study drugs were observed in 14 (56\%) and included thrombocytopenia, abnormal liver enzymes, rash, and hypertension.

Conclusions: Although the combination of pazopanib plus trametinib had acceptable toxicity with evidence of clinical activity, it did not achieve a statistically significant improvement in 4-month PFS over the prespecified null hypothesised 4-month PFS.

Cholangiocarcinoma refers to cancers of the bile duct that arise in the intrahepatic, perihilar, or distal (extrahepatic) biliary tree. Cholangiocarcinoma is a relatively rare cancer, accounting for $\sim 3 \%$ of all gastrointestinal malignancies, although the incidence of intrahepatic cholangiocarcinoma is increasing globally (Patel, 2001; Khan et al, 2008; Siegel et al, 2016). The majority of patients with

\footnotetext{
*Correspondence: Dr NS Azad; E-mail: nazad2@jhmi.edu

${ }^{3}$ These authors contributed equally to this work.
}

Received 3 January 2017; revised 5 April 2017; accepted 7 April 2017; published online 25 April 2017

(C) 2017 Cancer Research UK. All rights reserved 0007 - 0920/17 
cholangiocarcinoma have unresectable disease at the time of presentation, with $<5 \%$ of all patients surviving to 5 years (Shaib and El-Serag, 2004). Gemcitabine plus cisplatin is the standard of care first-line regimen for locally advanced or metastatic disease (Valle et al, 2010). No chemotherapy regimen has conclusively shown benefit in patients progressing after initial chemotherapy, and multiple retrospective studies suggest a progression-free survival (PFS) on second-line chemotherapy of 2-3 months (Lamarca et al, 2014; Rogers et al, 2014). Recent efforts have focussed on developing novel therapies for this disease.

The RAF/MEK/ERK signalling pathway is involved in the regulation of normal cell proliferation, survival, and differentiation, and this pathway is frequently aberrantly upregulated in a wide number of cancers including cholangiocarcinoma (Yoon et al, 2004; Roberts and Der, 2007; Schmitz et al, 2007; Wang et al, 2009). Alterations in this pathway have been reported in up to $35 \%$ and $55 \%$ of intrahepatic and extrahepatic cholangiocarcinomas, respectively (Churi et al, 2014). The MEK inhibitors have previously shown modest signs of activity in cholangiocarcinoma. In a 28-patient phase 1 clinical trial, the MEK $1 / 2$ inhibitor binimetinib (MEK162, ARRY438162) showed evidence of clinical efficacy with two objective responses ( $8 \%$ of subjects) and a $46 \%$ stable disease rate for a median duration of 5 months (Finn et al, 2012). Similarly, in a phase 2 clinical trial of the MEK $1 / 2$ inhibitor selumetinib (AZD6244, ARRY142886) in cholangiocarcinoma, 3 of 28 patients (12\%) had a confirmed objective response and 17 of 28 patients (68\%) had stable disease (Bekaii-Saab et al, 2011).

The vascular endothelial growth factor (VEGF) pathway is a principal mediator of tumour angiogenesis and is also implicated in the growth and metastasis of many cancers including cholangiocarcinoma (Leung et al, 1989; Folkman, 1990; Benckert et al, 2003; Park et al, 2006; Yoshikawa et al, 2008; Goel and Mercurio, 2013). In a retrospective pathologic study of 236 cases of cholangiocarcinoma, overexpression of VEGF was noted in more than half of all cases (Yoshikawa et al, 2008). Several small studies have previously been conducted with inhibitors of VEGF signalling in cholangiocarcinoma, with modest signs of activity. A phase 2 study of single agent sorafenib, a multitargeted kinase inhibitor that inhibits VEGF signalling, reported a $32.6 \%$ disease control rate at 12 weeks (Bengala et al, 2010). Limited antitumour activity was also reported in a separate phase 2 trial of sorafenib in cholangiocarcinoma (El-Khoueiry et al, 2012) and with other antiangiogenic agents: cabozantinib (Goyal et al, 2015), bevacizumab (Lubner et al, 2010), and sunitinib (Dreyer et al, 2015).

Although MEK inhibition and antiangiogenic therapies have each individually shown limited activity in cholangiocarcinoma, dual inhibition of these pathways has not been evaluated previously. Trametinib is an orally available highly specific inhibitor of MEK1 and MEK2 that is approved for BRAF V600E or V600K mutation-positive unresectable or metastatic melanoma (Flaherty et al, 2012; Infante et al, 2012; Robert et al, 2015). Pazopanib is an orally available multikinase inhibitor of VEGFR, PDGFR, KIT, FGFR, as well as RAF that is approved for advanced renal cell carcinoma and advanced refractory soft tissue sarcoma (Sternberg et al, 2010; Gril et al, 2011; van der Graaf et al, 2012). Together, pazopanib and trametinib provide vertical inhibition of the RAF/MEK/ERK signalling pathway through combined inhibition of RAF and MEK, as well as potent inhibition of VEGFR and PDGFR for inhibition of angiogenesis. Our group has demonstrated the synergistic effects of trametinib and pazopanib in thyroid cancer cell lines and xenograft models (Ball et al, 2015). In an exploratory phase 1 study in advanced solid tumours, we previously reported that pazopanib $800 \mathrm{mg}$ daily and trametinib $2 \mathrm{mg}$ daily was safe and tolerable (Azad et al, 2014). Two patients with cholangiocarcinoma were enrolled in our initial dose escalation study, with one patient attaining a prolonged partial response and the other patient with prolonged stable disease. Based on this initial signal of activity, we further evaluated the safety and efficacy of combination pazopanib plus trametinib in an expansion cohort of 25 pretreated patients with advanced cholangiocarcinoma.

\section{MATERIALS AND METHODS}

This was an open-label, multicentre (Sidney Kimmel Comprehensive Cancer Center (SKCCC) at John Hopkins University (JHU) and The University of Texas MD Anderson Comprehensive Cancer Center (MDACC)) trial supported by the National Comprehensive Cancer Network (NCCN). Patients $>18$ years old with advanced cholangiocarcinoma that was refractory to standard of care treatment options (or patients who refused standard of care treatment options) were eligible. Other eligibility criteria included the presence of Response Evaluation Criteria in Solid Tumors (RECIST) criteria 1.1 measurable disease (Eisenhauer et al, 2009), an Eastern Cooperative Oncology Group performance status $\leqslant 1$ and adequate organ function as defined by absolute neutrophil count $\geqslant 1500$ cells per $\mu$, platelet count $\geqslant 100000$ cells per $\mu \mathrm{l}$, international normalised ratio $\leqslant 1.2 \times$ upper limit of normal (unless stabilised with anticoagulation therapy and within the recommended range for the desired level of anticoagulation), total bilirubin $\leqslant 1.5 \times$ upper limit of normal (or, in patients with Gilbert syndrome, total bilirubin $>1.5 \times$ as long as direct bilirubin is normal), and serum creatinine $\leqslant 1.5 \times$ upper limit of normal or creatinine clearance $\geqslant 45 \mathrm{ml} \mathrm{min}^{-1}$, and urine protein to creatinine ratio $<1$ (or, if $>1,24$-h urine protein $<1$ g).

Evaluation and treatment. The protocol was approved by the institutional review board (IRB) at both study sites, and complied with the International Ethical Guidelines for Biomedical Research Involving Human Subjects and the Declaration of Helsinki. The study drugs (trametinib and pazopanib) were provided by GlaxoSmithKline (Brentford, UK) (eventually Novartis). Eligible patients were enrolled centrally at the SKCCC at JHU. The trial was registered under ClinicalTrials.gov as NCT01438554. All patients provided written informed consent before enrolment.

Patients received $800 \mathrm{mg}$ of pazopanib and $2.0 \mathrm{mg}$ of trametinib orally daily every day of a 28 -day cycle, a dose that was established in our initial dose escalation study across multiple tumour types. The treatment protocol allowed dose delays or reduction if patients experienced unacceptable side effects and adverse reactions. Patients were evaluated every cycle for trial therapy compliance and monitoring of adverse events. The National Cancer Institute Common Terminology Criteria for Adverse Events version 4.0 was implemented for adverse event monitoring (National Institute of Cancer, 2009). Disease assessments (computed tomography or magnetic resonance imaging) were performed every other cycle. Response was evaluated according to the RECIST, version 1.1 (Eisenhauer et al, 2009). Upon progression of disease, patients were monitored for long-term adverse events, new primary tumours, and survival.

Statistical methods. The primary outcome measure was 4-month PFS rate. Secondary outcome measures included overall survival (OS) duration and disease control rate (DCR), defined as the percentage of patients with no disease progression (complete response, partial response, or stable disease) by RECIST as a best response to therapy. Proportions are reported with exact 95\% binomial confidence intervals (CIs). Event time distributions for OS and PFS were estimated using the Kaplan-Meier method (Kaplan and Meier, 1958) and CIs were calculated using the Brookmeyer-Crowley method. Statistical analyses were performed using SAS version 9.2 (SAS Institute Inc., Cary, NC, USA) and R version 3.0. To determine the distribution of the follow-up times if no patient had died, we reversed the coding of the OS censoring 
indicator and censored deaths, and the previously censored patients were considered events. The median follow-up for the study was calculated from this curve. A null 4-month PFS of $25 \%$ was pre-established as a benchmark for the treatment of patients included in our study, based on a prior phase 2 study of sorafenib in unresectable cholangiocarcinoma that reported a median PFS of 2.3 months and a 4-month PFS of 25\% (Bengala et al, 2010). We aimed to demonstrate a 4-month PFS that was significantly higher than this historical benchmark. For the purposes of monitoring, a nonparametric Kaplan-Meier estimate at 4 months was utilised with a planned interim analysis for futility after 10 of 25 patients were enrolled.

\section{RESULTS}

Patients. From September 2013 until September 2014, 25 patients with advanced cholangiocarcinoma were enrolled at MD Anderson Cancer Center ( $n=18$ patients) and Johns Hopkins University $(n=7)$ in this expansion cohort of pazopanib plus trametinib. Although the original study design included an interim analysis for futility, the interim analysis was not able to be performed due to rapid study accrual. The clinicopathological characteristics of the patients entered into this study are shown in Table 1. Patients had received a median of 2 prior systemic therapies for cholangiocarcinoma (range 1-7). Several patients had received prior antiangiogenesis therapy including sorafenib $(n=1)$, sunitinib $(n=1)$, or a bevacizumab-containing regimen $(n=4)$. No patients had received prior therapy with a MEK inhibitor. All patients were treated according to the study protocol, and no patients remain on study at the time of this analysis.

Efficacy. Of the 25 patients enrolled in the study, 20 (80\%) were evaluable for objective response. Five patients were not evaluable for objective response because they did not complete one 28-day cycle of therapy or did not have their disease re-evaluated after starting therapy. Responses ranged from progressive disease to a decrease in target lesions of $30 \%$ by RECIST 1.1 (see Figure 1). A partial response occurred in one (5\%) of the evaluable patients (95\% CI: $0.13-24.9 \%$ ). This patient had a response to therapy that lasted $\sim 6$ months. The DCR was 15 out of 20 (75\%) (95\% CI: 51$91 \%)$. A total of five patients were determined to have progressive disease as a best response to therapy. Of these five patients, three patients had stable target lesions but in one case developed new lesions, and in the other two cases had a significant increase in the size of nontarget lesions. Of the five inevaluable patients, one patient withdrew consent for the study, one patient withdrew for treatment toxicity including thrombocytopenia and fatigue, and three patients were withdrawn from study for adverse events unrelated to therapy.

Figures 2 and 3 show the Kaplan-Meier curves for PFS and OS for all 25 study patients. The PFS and OS data have matured for all patients. The median PFS was 3.6 months (95\% CI: 2.7-5.1). The 2-month PFS was $72 \%$ (95\% CI: 56-92), and the 4-month PFS was 40\% (95\% CI: $24.7-64.6 \%)$. The 4-month PFS did not differ significantly from a prespecified null hypothesised 4-month PFS of $25 \%, P=0.063$. The median survival was 6.4 months (95\% CI: $4.3-$ 10.2). The 2-, 4-, and 6-month OS rates were 88 (95\% CI: 76$100 \%), 76$ (95\% CI: 61-95\%), and 52 (95\% CI: 36-76\%), respectively.

Adverse events. The median duration of treatment was 12 weeks. Four patients $(16 \%)$ discontinued treatment because of treatment toxicity. The median time to treatment discontinuation for these patients was $\sim 8$ weeks. The treatment dose of either pazopanib or trametinib was reduced in 9 of 25 (36\%) patients due to adverse events. Of those who required a dose reduction, trametinib was reduced from $2 \mathrm{mg}$ daily to $1.5 \mathrm{mg}$ daily in 8 patients. One patient
Table 1. Baseline patient characteristics

\begin{tabular}{|c|c|}
\hline Characteristic & \\
\hline $\begin{array}{l}\text { Age, years } \\
\text { Median } \\
\text { Range }\end{array}$ & $\begin{array}{c}62 \\
38-80\end{array}$ \\
\hline $\begin{array}{l}\text { Sex, number (\%) } \\
\text { Male } \\
\text { Female }\end{array}$ & $\begin{array}{l}14(56 \%) \\
11(44 \%)\end{array}$ \\
\hline $\begin{array}{l}\text { Race, number (\%) } \\
\text { White } \\
\text { Black } \\
\text { Asian } \\
\text { Unknown or other }\end{array}$ & $\begin{array}{l}19(76 \%) \\
3(12 \%) \\
1(4 \%) \\
2(8 \%)\end{array}$ \\
\hline $\begin{array}{l}\text { Previous chemotherapy regimens for advanced disease, } \\
\text { number } \\
\text { Median } \\
\text { Range }\end{array}$ & $\begin{array}{c}2 \\
1-7\end{array}$ \\
\hline Prior radiation therapy for cholangiocarcinoma, number (\%) & $11(44 \%)$ \\
\hline $\begin{array}{l}\text { Treatment site, number (\%) } \\
\text { MD Anderson Cancer Center } \\
\text { Johns Hopkins University }\end{array}$ & $\begin{array}{r}18(72 \%) \\
7(28 \%)\end{array}$ \\
\hline $\begin{array}{l}\text { ECOG performance status, number (\%) } \\
0 \\
1\end{array}$ & $\begin{array}{l}10(40 \%) \\
15(60 \%)\end{array}$ \\
\hline $\begin{array}{l}\text { Cholangiocarcinoma subtype, number (\%) } \\
\text { Intrahepatic } \\
\text { Perihilar or distal }\end{array}$ & $\begin{array}{r}5(20 \%) \\
20(80 \%)\end{array}$ \\
\hline
\end{tabular}

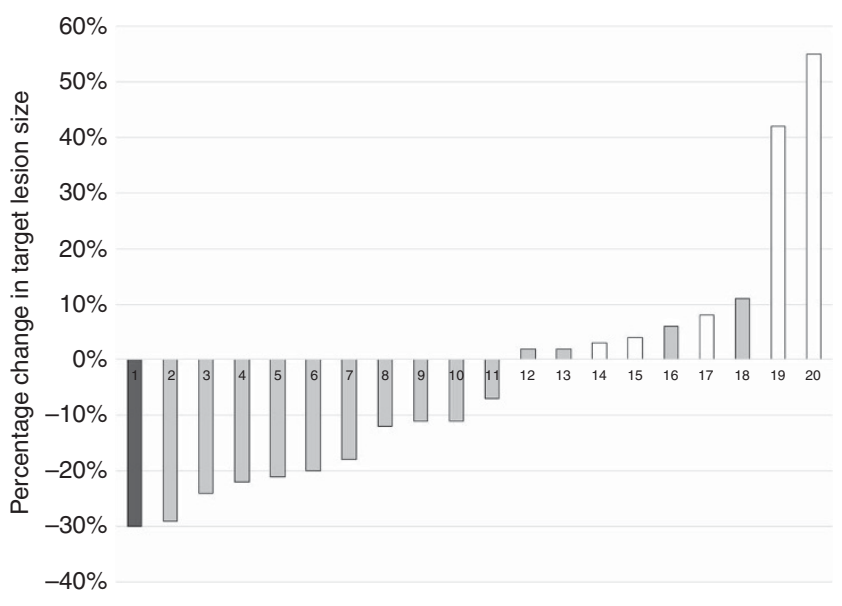

- Partial response $\square$ Stable disease $\square$ Progressive disease

Figure 1. Best response per RECIST 1.1.

required further dose reduction to $1 \mathrm{mg}$ daily, whereas one patient who initially required a dose reduction of trametinib due to a rash was able to resume full dosing of trametinib after resolution of the adverse event. The most common reason for a dose reduction of trametinib was a rash. Pazopanib was dose reduced from 800 to $600 \mathrm{mg}$ in 6 patients. Two patients necessitated further dose reduction of pazopanib, to $400 \mathrm{mg}$ daily in one patient and to discontinuation of pazopanib in another patient. Thrombocytopenia was the most common reason for dose reduction of pazopanib. Drug interruptions were required as a result of adverse events in 11 (44\%) patients. The median duration of dose interruptions was 9 days. The most common reasons for dose interruptions were rash, hypertension, abnormal liver enzymes, thrombocytopenia, and gastrointestinal side effects including nausea, vomiting, or diarrhoea. 


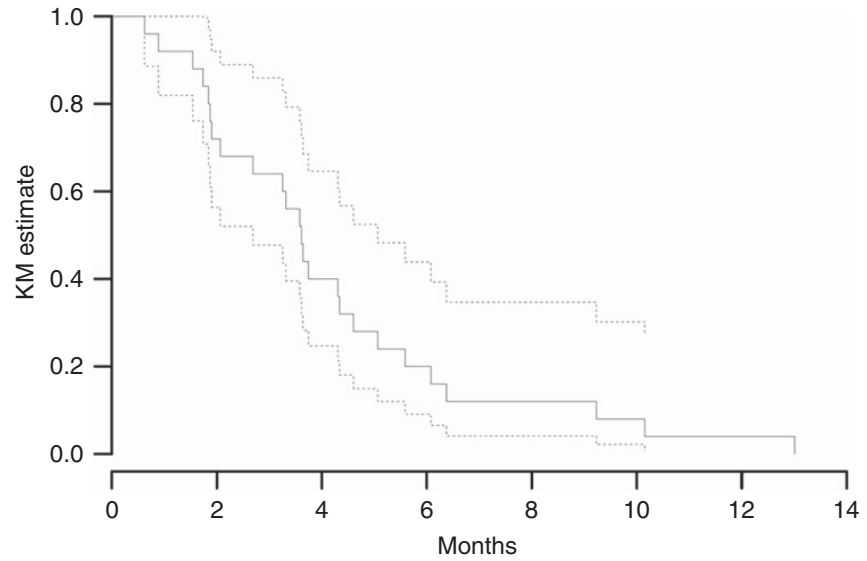

Figure 2. Kaplan-Meier (KM) estimate of progression-free survival (PFS) for patients in the study. The median PFS was 3.6 months. The dotted lines represent $95 \%$ confidence intervals.

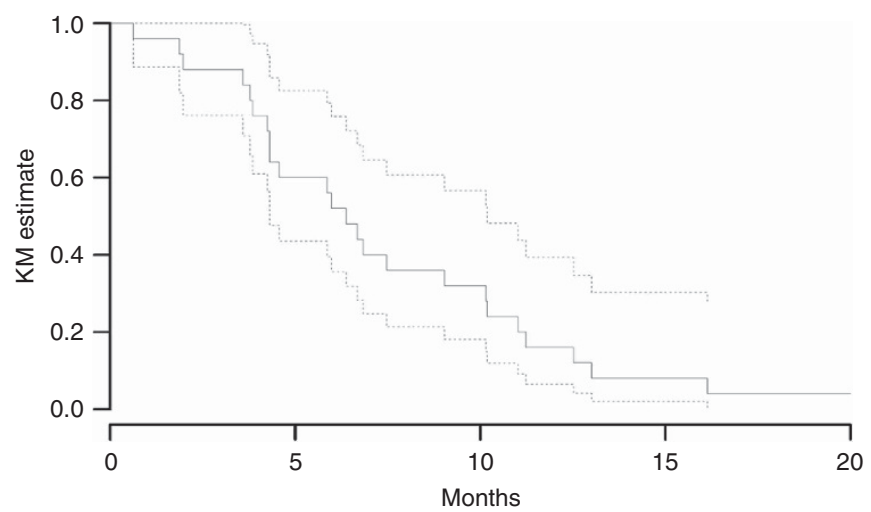

Figure 3. Kaplan-Meier (KM) estimate of overall survival (OS) for patients in the study. The median OS was 6.4 months. The dotted lines represent $95 \%$ confidence intervals.

Treatment-related toxicities observed in two or more participants, and all grade 3/4 treatment-related toxicities, are listed in Table 2. Treatment-related toxicities were predominantly of mild or moderate severity, with the most common events including rash (80\% of patients), hypertension (64\%), nausea or vomiting $(64 \%)$, fatigue $(60 \%)$, diarrhoea (52\%), and thrombocytopenia (40\%). In most cases, rash was treated successfully with topical steroids as well as dosage reductions or interruptions of trametinib. Similarly, hypertension was managed successfully in most cases with antihypertensive agents and dose reduction or interruption of pazopanib and trametinib. Grade 3-4 treatment-related toxicities were observed in 14 (56\%) of patients and included hypertension, fatigue, rash, diarrhoea, anaemia, thrombocytopenia, amnesia, and one case of posterior reversible encephalopathy syndrome (PRES) syndrome, also known as reversible posterior leukoencephalopathy syndrome (RPLS), in a patient with refractory hypertension. Thrombocytopenia was the most common severe treatment-related toxicity, and was managed with pazopanib dose interruption and dose reduction. There were no treatment-related deaths.

\section{DISCUSSION}

Cholangiocarcinoma is an aggressive disease with a poor prognosis and no clear therapy options in the refractory setting. Here, we report the results of a nonrandomised expansion cohort of combination pazopanib and trametinib therapy in 25 patients
Table 2. Treatment-related adverse events occurring in two or more participants, and all grade 3/4 treatment-related adverse events

\begin{tabular}{|c|c|c|c|c|}
\hline \multirow[b]{2}{*}{ Event } & \multicolumn{2}{|c|}{ Grades 1-2 } & \multicolumn{2}{|c|}{ Grades 3-4 } \\
\hline & \begin{tabular}{|l|} 
No. of \\
patients
\end{tabular} & $\%$ & $\begin{array}{c}\text { No. of } \\
\text { patients }\end{array}$ & $\%$ \\
\hline \multicolumn{5}{|l|}{ Cardiorenal } \\
\hline Oedema, facial & 3 & 12 & & \\
\hline Oedema, limbs & 4 & 16 & & \\
\hline Elevated creatinine & 2 & 8 & & \\
\hline Hypertension & 16 & 64 & 2 & 8 \\
\hline Hypomagnesaemia & 7 & 28 & & \\
\hline Hyponatraemia & 2 & 8 & & \\
\hline Proteinuria & 3 & 12 & & \\
\hline \multicolumn{5}{|l|}{ Constitutional } \\
\hline Dehydration & 2 & 8 & & \\
\hline Fatigue & 15 & 60 & 1 & 4 \\
\hline \multicolumn{5}{|l|}{ Dermatologic } \\
\hline Dry skin & 3 & 12 & & \\
\hline Finger or nail changes & 3 & 12 & & \\
\hline Rash & 20 & 80 & 3 & 12 \\
\hline \multicolumn{5}{|l|}{ Gastrointestinal } \\
\hline Anorexia & 9 & 36 & & \\
\hline Constipation & 3 & 12 & & \\
\hline Diarrhoea & 13 & 52 & 1 & 4 \\
\hline Elevated liver function tests & 8 & 32 & 3 & 12 \\
\hline Mucositis & 2 & 8 & & \\
\hline Nausea or vomiting & 16 & 64 & 2 & 8 \\
\hline \multicolumn{5}{|l|}{ HEENT } \\
\hline Blurry vision & 5 & 20 & & \\
\hline Change in taste & 6 & 24 & & \\
\hline Congestion or postnasal drip & 2 & 8 & & \\
\hline Floaters & 2 & 8 & & \\
\hline \multicolumn{5}{|l|}{ Haematologic } \\
\hline Anaemia & 3 & 12 & 1 & 4 \\
\hline Bleeding or bruising & 7 & 28 & & \\
\hline Neutropenia & 3 & 12 & & \\
\hline Thrombocytopenia & 10 & 40 & 6 & 24 \\
\hline \multicolumn{5}{|l|}{ Neurological } \\
\hline Amnesia & 1 & 4 & 1 & 4 \\
\hline Dizziness & 2 & 8 & & \\
\hline Dysgeusia & 2 & 8 & & \\
\hline Headache & 2 & 8 & & \\
\hline $\begin{array}{l}\text { Posterior reversible } \\
\text { encephalopathy syndrome (PRES) }\end{array}$ & 1 & 4 & 1 & 4 \\
\hline
\end{tabular}

with highly refractory cholangiocarcinoma who had received a median of 2 prior systemic therapies. Together, pazopanib and trametinib provide inhibition of angiogenesis and RAF/MEK/ERK signalling, two pathways that have been identified as therapeutic targets for cholangiocarcinoma. Although limited activity was previously described with inhibitors of either pathway, to our knowledge dual inhibition of these pathways has not been explored previously in this cancer subtype.

In this trial, our observed median PFS is reflective of the aggressive nature of refractory cholangiocarcinoma. Although cross-trial comparisons in the context of this heavily pretreated subset of patients must be made only with caution, the observed PFS compares favourably with other trials in refractory cholangiocarcinoma (Shaib and El-Serag, 2004; Lamarca et al, 2014). Although there was a trend towards increased 4-month PFS as compared with the prespecified null hypothesised 4-month PFS, this difference did not reach statistical significance. On this basis, the trial did not achieve the prespecified target to justify further clinical development of this combination in cholangiocarcinoma. 
However, the disease response and the $75 \%$ disease control rate suggests that a subset of patients may benefit from this therapy and that further clinical investigation may be warranted, potentially of a biomarker-based approach that can prospectively identify patients to be treated. Mutations in the RAS/RAF/MEK/ERK pathway as well as PI3 Kinase/AKT have been reported in this entity and could rationally be evaluated as predictive biomarkers of this regimen. Additional studies are needed to explore potential molecular phenotype(s) of patients in whom the combination of a MEK inhibitor and antiangiogenic therapy may provide more clinical benefit. Although the clinical activity of MEK inhibitors in cholangiocarcinoma has been presumed to be due to on-targeted inhibition of the RAF/MEK/ERK signalling pathway, it is notable that two of the most dramatic responses previously observed did not have any detectable driver mutations in this signalling pathway (Finn et al, 2012). Therefore, the mechanism of action of MEK inhibition in cholangiocarcinoma remains somewhat unclear and may be more complex than previously assumed. Recently, MEK inhibitors have been found to have important immune modulatory properties (Liu et al, 2015; Bendell et al, 2016; Ebert et al, 2016), and the VEGF signalling pathway has also been implicated as a mechanism of tumour immune escape (Goel and Mercurio, 2013). This raises the possibility that some the clinical activity of these agents in cholangiocarcinoma may in part be immunologically mediated, and further investigation of one or more of these agents in combination with novel immunotherapies may be warranted.

The reported adverse events are similar to those observed in a prior dose escalation trial of pazopanib and trametinib in advanced solid tumours, and are also consistent with the known toxic effects of each individual agent. Although this trial was nonrandomised, the observed rate of serious treatment-related adverse events (56\%) was somewhat higher than the rate observed in prior registration trials of each agent alone (Sternberg et al, 2010; Flaherty et al, 2012; van der Graaf et al, 2012), suggesting that there is additive toxicity when these agents are combined. As monotherapy, pazopanib and trametinib have overlapping toxicity profiles that include rash, fatigue, and diarrhoea, and therefore additive toxicity with this combination was anticipated. Although rash was the most common adverse events, a severe rash was uncommon and most cases were managed successfully with topical steroids, dose reductions, or treatment interruption. The toxicity of pazopanib plus trametinib remains an important consideration, and close monitoring of patients and optimisation of toxicity management are needed for further development of this treatment combination. The dose reductions seen in this trial should be seen as part of an ongoing dialogue in the drug development community about whether the definition of maximum tolerated dose should include ongoing toxicity and dose adjustments past the usual first cycle of therapy, as has been the standard.

In conclusion, we find that the combination of pazopanib and trametinib has signs of possible cumulative toxicity, requiring frequent dose reductions, and has modest clinical activity in advanced refractory cholangiocarcinoma. Further studies are needed to better characterise the benefit of combination antiangiogenic therapy with MEK inhibition, and to explore molecular phenotypes in which this combination may provide more significant benefit.

\section{ACKNOWLEDGEMENTS}

We thank the patients and their families for participating in this study. This study was approved and funded by the National Comprehensive Cancer Network (NCCN) Oncology Research Program (ORP) from general research support provided by Novartis Pharmaceuticals Corporation (formerly GlaxoSmithKline,
LLC). This work was partially supported by the National Institutes of Health grant (T32 CA009071 to MY).

\section{CONFLICT OF INTEREST}

The authors declare no conflict of interest.

\section{REFERENCES}

Azad N, Ball D, Sherman S, Rudek M, Falchook G, Nelkin B, Janku F, Papadopoulos N, O’Conner A, Ahmed S, Wilky B, Markus S, Gong J, Cosgrove D, Zahurak M, Zinner R, Kurzrock R (2014) Abstract B279: A phase I study determining the safety and tolerability of combination therapy with Pazopanib (P), a VEGFR/PDGFR/Raf inhibitor, and GSK1120212 (Trametinib: T), a MEK inhibitor, in advanced solid tumors with expansion cohorts in advanced differentiated thyroid cancer (DTC), cholangiocarcinoma (ChCA), and soft tissue sarcoma (STS). Mol Cancer Ther 12(11 Suppl): B279.

Ball DW, Jin N, Xue P, Bhan S, Ahmed SR, Rosen DM, Schayowitz A, Clark DP, Nelkin BD (2015) Trametinib with and without pazopanib has potent preclinical activity in thyroid cancer. Oncol Rep 34: 2319-2324.

Bekaii-Saab T, Phelps MA, Li X, Saji M, Goff L, Kauh JSW, O'Neil BH, Balsom S, Balint C, Liersemann R, Vasko V V, Bloomston M, Marsh W, Doyle LA, Ellison G, Grever M, Ringel MD, Villalona-Calero MA (2011) Multi-institutional phase II study of selumetinib in patients with metastatic biliary cancers. J Clin Oncol 29: 2357-2363.

Benckert C, Jonas S, Cramer T, Von Marschall Z, Schäfer G, Peters M, Wagner K, Radke C, Wiedenmann B, Neuhaus P, Höcker M, Rosewicz S (2003) Transforming growth factor beta 1 stimulates vascular endothelial growth factor gene transcription in human cholangiocellular carcinoma cells. Cancer Res 63: 1083-1092.

Bendell J, Won KT, Ean CC, Yung-Jue B, Lee C, Desai J, Lewin J, Wallin J, Thakur M, Das, Mwawasi G, Cha E, Infante J (2016) Safety and efficacy of cobimetinib (cobi) and atezolizumab (atezo) in a Phase $1 \mathrm{~b}$ study of metastatic colorectal cancer (mCRC). Ann Oncol 27: ii140.

Bengala C, Bertolini F, Malavasi N, Boni C, Aitini E, Dealis C, Zironi S, Depenni R, Fontana A, Del Giovane C, Luppi G, Conte P (2010) Sorafenib in patients with advanced biliary tract carcinoma: a phase II trial. $\mathrm{Br} \mathrm{J}$ Cancer 102: 68-72.

Churi CR, Shroff R, Wang Y, Rashid A, Kang HC, Weatherly J, Zuo M, Zinner R, Hong D, Meric-Bernstam F, Janku F, Crane CH, Mishra L, Vauthey JN, Wolff RA, Mills G, Javle M, Creighton C (2014) Mutation profiling in cholangiocarcinoma: prognostic and therapeutic implications. PLoS One 9: e115383.

Dreyer C, Sablin M-P, Bouattour M, Neuzillet C, Ronot M, Dokmak S, Belghiti J, Guedj N, Paradis V, Raymond E, Faivre S (2015) Disease control with sunitinib in advanced intrahepatic cholangiocarcinoma resistant to gemcitabine-oxaliplatin chemotherapy. World J Hepatol 7: 910-915.

Ebert PJR, Cheung J, Yang Y, McNamara E, Hong R, Moskalenko M, Gould SE, Maecker H, Irving BA, Kim JM, Belvin M, Mellman I (2016) MAP kinase inhibition promotes $\mathrm{T}$ cell and anti-tumor activity in combination with PD-L1 checkpoint blockade. Immunity 44: 609-621.

Eisenhauer EA, Therasse P, Bogaerts J, Schwartz LH, Sargent D, Ford R, Dancey J, Arbuck S, Gwyther S, Mooney M, Rubinstein L, Shankar L, Dodd L, Kaplan R, Lacombe D, Verweij J (2009) New response evaluation criteria in solid tumours: revised RECIST guideline (version 1.1). Eur J Cancer 45: 228-247.

El-Khoueiry AB, Rankin CJ, Ben-Josef E, Lenz H-J, Gold PJ, Hamilton RD, Govindarajan R, Eng C, Blanke CD (2012) SWOG 0514: a phase II study of sorafenib in patients with unresectable or metastatic gallbladder carcinoma and cholangiocarcinoma. Invest New Drugs 30: 1646-1651.

Finn RS, Javle MM, Tan BR, Weekes CD, Bendell JC, Patnaik A, Khan GN, Laheru D, Anderson L, Christy-Bittel JL, Barrett E, Guthrie K, Litwiler KS, Bekaii-Saab TS (2012) A phase I study of MEK inhibitor MEK162 (ARRY-438162) in patients with biliary tract cancer. ASCO Meet Abstr 30: 220 .

Flaherty KT, Robert C, Hersey P, Nathan P, Garbe C, Milhem M, Demidov L V., Hassel JC, Rutkowski P, Mohr P, Dummer R, Trefzer U, Larkin JMG, Utikal J, Dreno B, Nyakas M, Middleton MR, Becker JC, Casey M, 
Sherman LJ, Wu FS, Ouellet D, Martin A-M, Patel K, Schadendorf D (2012) Improved survival with MEK inhibition in BRAF-mutated melanoma. N Engl J Med 367: 107-114.

Folkman J (1990) What is the evidence that tumors are angiogenesis dependent? J Natl Cancer Inst 82: 4-6.

Goel HL, Mercurio AM (2013) VEGF targets the tumour cell. Nat Rev Cancer 13: 871-882.

Goyal L, Yurgelun MB, Abrams TA, Kwak EL, Cleary JM, Knowles M, Regan E, Gisondi A, Sheehan S, Zheng H, Zhu AX (2015) A phase II trial of cabozantinib (XL-184) in patients with advanced cholangiocarcinoma. ASCO Meet Abstr 33: 800 .

Gril B, Palmieri D, Qian Y, Smart D, Ileva L, Liewehr DJ, Steinberg SM, Steeg PS (2011) Pazopanib reveals a role for tumor cell B-Raf in the prevention of HER2 + breast cancer brain metastasis. Clin Cancer Res 17: $142-153$.

Infante JR, Fecher LA, Falchook GS, Nallapareddy S, Gordon MS, Becerra C, DeMarini DJ, Cox DS, Xu Y, Morris SR, Peddareddigari VG, Le NT, Hart L, Bendell JC, Eckhardt G, Kurzrock R, Flaherty K, Burris HA, Messersmith WA (2012) Safety, pharmacokinetic, pharmacodynamic, and efficacy data for the oral MEK inhibitor trametinib: a phase 1 doseescalation trial. Lancet Oncol 13: 773-781.

Kaplan EL, Meier P (1958) Nonparametric estimation from incomplete observations. J Am Stat Assoc 53: 457-481.

Khan SA, Toledano MB, Taylor-Robinson SD (2008) Epidemiology, risk factors, and pathogenesis of cholangiocarcinoma. HPB (Oxford) 10: 77-82.

Lamarca A, Hubner RA, David Ryder W, Valle JW (2014) Second-line chemotherapy in advanced biliary cancer: a systematic review. Ann Oncol 25: $2328-2338$.

Leung DW, Cachianes G, Kuang WJ, Goeddel D V, Ferrara N (1989) Vascular endothelial growth factor is a secreted angiogenic mitogen. Science 246: 1306-1309.

Liu L, Mayes PA, Eastman S, Shi H, Yadavilli S, Zhang T, Yang J, Seestaller-Wehr L, Zhang SY, Hopson C, Tsvetkov L, Jing J, Zhang S, Smothers J, Hoos A (2015) The BRAF and MEK inhibitors dabrafenib and trametinib: Effects on immune function and in combination with immunomodulatory antibodies targeting PD-1, PD-L1, and CTLA-4. Clin Cancer Res 21: 1639-1651.

Lubner SJ, Mahoney MR, Kolesar JL, Loconte NK, Kim GP, Pitot HC, Philip PA, Picus J, Yong W-P, Horvath L, Van Hazel G, Erlichman CE, Holen KD (2010) Report of a multicenter phase II trial testing a combination of biweekly bevacizumab and daily erlotinib in patients with unresectable biliary cancer: a phase II Consortium study. J Clin Oncol 28 : 3491-3497.

National Institute of Cancer (2009) Common Terminology Criteria for Adverse Events (CTCAE) Common Terminology Criteria for Adverse Events v4.0 (CTCAE). NIH Publ 0-71.

Park BK, Paik Y-H, Park JY, Park KH, Bang S, Park SW, Chung JB, Park YN, Song SY (2006) The clinicopathologic significance of the expression of vascular endothelial growth factor-C in intrahepatic cholangiocarcinoma. Am J Clin Oncol 29: 138-142.

Patel T (2001) Increasing incidence and mortality of primary intrahepatic cholangiocarcinoma in the United States. Hepatology 33: 1353-1357.
Robert C, Karaszewska B, Schachter J, Rutkowski P, Mackiewicz A, Stroiakovski D, Lichinitser M, Dummer R, Grange F, Mortier L, Chiarion-Sileni V, Drucis K, Krajsova I, Hauschild A, Lorigan P, Wolter P, Long G V., Flaherty K, Nathan P, Ribas A, Martin A-M, Sun P, Crist W, Legos J, Rubin SD, Little SM, Schadendorf D (2015) Improved overall survival in melanoma with combined dabrafenib and trametinib. $N$ Engl $J$ Med 372: 30-39.

Roberts PJ, Der CJ (2007) Targeting the Raf-MEK-ERK mitogen-activated protein kinase cascade for the treatment of cancer. Oncogene 26: 3291-3310.

Rogers JE, Law L, Nguyen VD, Qiao W, Javle MM, Kaseb A, Shroff RT (2014) Second-line systemic treatment for advanced cholangiocarcinoma. $J$ Gastrointest Oncol 5: 408-413.

Schmitz KJ, Lang H, Wohlschlaeger J, Sotiropoulos GC, Reis H, Schmid KW, Baba HA (2007) AKT and ERK1/2 signaling in intrahepatic cholangiocarcinoma. World J Gastroenterol 13: 6470-6477.

Shaib Y, El-Serag HB (2004) The epidemiology of cholangiocarcinoma. Semin Liver Dis 24: 115-125.

Siegel RL, Miller KD, Jemal A (2016) Cancer statistics, 2016. CA Cancer J Clin 66: 7-30.

Sternberg CN, Davis ID, Mardiak J, Szczylik C, Lee E, Wagstaff J, Barrios CH, Salman P, Gladkov OA, Kavina A, Zarbá JJ, Chen M, McCann L, Pandite L, Roychowdhury DF, Hawkins RE (2010) Pazopanib in locally advanced or metastatic renal cell carcinoma: results of a randomized phase III trial. J Clin Oncol 28: 1061-1068.

Valle J, Wasan H, Palmer DH, Cunningham D, Anthoney A, Maraveyas A, Madhusudan S, Iveson T, Hughes S, Pereira SP, Roughton M, Bridgewater J (2010) Cisplatin plus gemcitabine versus gemcitabine for biliary tract cancer. $N$ Engl J Med 362: 1273-1281.

van der Graaf WT, Blay J-Y, Chawla SP, Kim D-W, Bui-Nguyen B, Casali PG, Schöffski P, Aglietta M, Staddon AP, Beppu Y, Le Cesne A, Gelderblom H, Judson IR, Araki N, Ouali M, Marreaud S, Hodge R, Dewji MR, Coens C, Demetri GD, Fletcher CD, Dei Tos AP, Hohenberger P (2012) Pazopanib for metastatic soft-tissue sarcoma (PALETTE): a randomised, doubleblind, placebo-controlled phase 3 trial. Lancet 379: 1879-1886.

Wang C, Maass T, Krupp M, Thieringer F, Strand S, Wörns MA, Barreiros A-P, Galle PR, Teufel A (2009) A systems biology perspective on cholangiocellular carcinoma development: focus on MAPK-signaling and the extracellular environment. J Hepatol 50: 1122-1131.

Yoon J-H, Gwak G-Y, Lee H-S, Bronk SF, Werneburg NW, Gores GJ (2004) Enhanced epidermal growth factor receptor activation in human cholangiocarcinoma cells. J Hepatol 41: 808-814.

Yoshikawa D, Ojima H, Iwasaki M, Hiraoka N, Kosuge T, Kasai S, Hirohashi S, Shibata T (2008) Clinicopathological and prognostic significance of EGFR, VEGF, and HER2 expression in cholangiocarcinoma. Br J Cancer 98: 418-425.

This work is published under the standard license to publish agreement. After 12 months the work will become freely available and the license terms will switch to a Creative Commons AttributionNonCommercial-Share Alike 4.0 Unported License. 